The Egyptian Journal of Hospital Medicine (July 2019) Vol. 76 (2), Page 3494-3499

\title{
Phytoestrogens Soymilk and Fenugreek Oil Perturb Lipid and Hormonal Profile and Other Physiological Parameters of Male Albino Rats Eman G.E. Helal ${ }^{1}$, Hewaida, A.E. Fadal ${ }^{2}$, Gavin C. Ikechukwu ${ }^{3}$, Mohamed A. Abd-El-Aziz ${ }^{4}$, Shaimaa S. Ahmed ${ }^{1}$
}

${ }^{1}$ Zoology Department, Faculty of Science, Al-Azhar University (Girls), ${ }^{2}$ Physiology and Nutritional Chemistry, National Nutrition Institute, Cairo, Egypt ${ }^{3}$ Biochemistry Department, College of Natural Sciences, Michael Okpara University of Agriculture, Umudike, Nigeria, ${ }^{4}$ Physiology Department, Faculty of Medicine, Al-Azhar University

(Boys), Cairo, Egypt

*Corresponding Author: Eman G.E. Helal, E-mail: emanhelal@ hotmail.com, Mobile: 00201001025364, Orchid.org/0000-00030527-7028.

\begin{abstract}
Background: phytoestrogens are a diverse group of plant-derived compounds that structurally or functionally mimic mammalian estrogens. They have been investigated at the epidemiological, clinical and molecular levels to determine their potential health benefits.
\end{abstract}

Aim: the present study was carried out to investigate some biochemical effects of fenugreek oil and soymilk on male albino rats.

Materials and Methods: eighteen (18) animals were divided randomly into three groups with 6 animals per group. Group "1" received normal saline $1 \mathrm{~mL} / \mathrm{kg}$ body weight orally for four weeks. Group "2" rats were treated with oral dose of soymilk $1 \mathrm{ml} / \mathrm{kg}$ body weight/day once daily for four weeks, while rats in group "3" were treated with oral dose of fenugreek $1 \mathrm{ml} / \mathrm{kg}$ body weight/day once daily for four weeks. Blood samples were collected on the last day of the experiment for biochemical analysis.

Results: the fenugreek oil and soymilk induced highly significant decrease $(\mathrm{p}<0.01)$ in total cholesterol, triacylglycerol, low-density lipoprotein, very low-density lipoprotein, low-density lipoprotein high-density lipoprotein ratio (LDL/HDL) and a significant increase $(\mathrm{p}<0.05)$ in high-density lipoprotein. The results also showed highly significant decrease in follicle stimulating hormone, luteinizing hormone, testosterone and sperm count compared to normal control group.

Conclusion: the results of this study suggest that high levels of fenugreek and soymilk intake can cause hormonal disturbance and decrease sperm count.

Keywords: Fenugreek oil, Soymilk, Lipid profile, Phytoestrogen, Hormonal profile.

\section{INTRODUCTION}

Phytoestrogen are plant-derived compounds which have estrogenic effect and have been investigated for their health benefits ${ }^{(1)}$.

Milk is a naturally valuable source of vitamins and minerals such as vitamin $A$, vitamin $B_{6}$, vitamin $B_{12}$, thiamin, riboflavin, niacin, calcium, phosphorus, magnesium, zinc and potassium ${ }^{(\mathbf{1})}$. Soymilk is also consumed as an alternative drink to cow's milk. In addition to the essential proteins it contains, other health benefits of consuming milk are widely recognized such as improvement of bone health blood cholesterol, protection against cardiovascular disease, reduced colon cancer risk, reduced blood pressure, body weight regulation, protection of tooth enamel and reduced risk of type 2 diabetes. Soymilk is rich in isoflavones. The presence of isoflavones is the most important and unique benefit of soymilk. Each cup of soymilk contains about $20 \mathrm{mg}$ isoflavones (mainly genistein anddaidzein). Isoflavones have many health benefits including reduction of cholesterol, easing of menopause symptoms, prevention of osteoporosis and reducing the risk of breast cancer. Estrogen stimulates the multiplication and growth of cancer cells in the breast ${ }^{(2)}$. Isoflavones as phytoestrogens, inhibit the action of estrogens which in turn prevent the proliferation of breast cancer cells and have been linked to selective estrogen receptor modulators (SERM). Ingestion of isoflavone exerts biological effect in pre-and postmenopausal women. Hence, the risk of breast cancer can be reduced to a great extent by the use of soy-based products ${ }^{(3)}$. Isoflavones are also antioxidants which protect our cells and DNA against oxidation $^{(\mathbf{1})}$.

The fenugreek (Trigonella foenum-graecum L.) belongs to the family Fabaceae and is a multiuse and commercially important spice crop grown for its seeds, tender shoots, and fresh leaves. Fenugreek has economic value as food, medicine and in cosmetics ${ }^{(4)}$. Ethiopia, Egypt, and Turkey are the major countries for seed production. Fenugreek is known to have several pharmacological effects such as: hypoglycemic ${ }^{(5)}$ and antilipidemic or hypocholesterolemic effects ${ }^{(6)}$. Furthermore, this plant has shown antioxidant action ${ }^{(7)}$, gastroprotective activity ${ }^{(\mathbf{8})}$, appetite stimulation ${ }^{\left({ }^{(9)}\right.}$ and antirheumatic action ${ }^{(\mathbf{1 0})}$. Fenugreek is used as herbal medicine for treating metabolic and nutritive dysfunctions. Some studies indicate that fenugreek seed extract supplementation reduces the body and adipose 
ejhm.journals.ekb.eg

tissue weight ${ }^{(11,12)}$ and possess estrogenic effect due to the presence of flavonoids ${ }^{\mathbf{( 1 3})}$. Activities of fenugreek oils and extracts are attributed to a variety of its constituents. Fenugreek seed contains $45-60 \%$ carbohydrates, mainly mucilaginous fiber (galactomannans); $20-30 \%$ proteins high in lysine and tryptophan and 5-10\% fixed oils (lipids); pyridine-type alkaloids, mainly trigonelline (0.2$0.36 \%)$, choline $(0.5 \%)$, gentianine, and carpaine. Besides, the flavonoids apigenin, luteolin, orientin, quercetin, vitexin, and isovitexin and free amino acids, such as 4-hydroxyisoleucine (0.09 \%); arginine, histidine, and lysine; Calcium and iron; saponins (0.6-1.7

$\%)$; glycosides yielding steroidal sapogenins on hydrolysis (diosgenin, yamogenin, tigogenin, neotigogenin); cholesterol and sitosterol; vitamins A, B1,C, and nicotinic acid and $0.015 \%$ volatile oils (nalkanes and sesquiterpenes), which are thought to account for many of its presumed therapeutic effects ${ }^{(\mathbf{1 3})}$. There has been no comprehensive study comparing the effects of soymilk and fenugreek oil on lipid profile and hormonal profile.

\section{AIM OF STUDY}

This study aimed at evaluating the effects of fenugreek oil as a phytoestrogen as it is compared to soymilk and thus determining the extent of beneficial or adverse effect exhibited by both sources on lipid and hormonal profile as well as other physiological parameters.

\section{MATERIALS AND METHODS}

Fennel oil was purchased from Cap Pharm for Extracting Natural Oils \& Herbs, Cairo, Egypt and soymilk was purchased from a hypermarket. The study was approved by the Ethics Board of Al-Azhar University. This study was conducted in accordance with ethical procedures and policies approved by Animal Care and Use Committee of Faculty of Medicine, Al-Azhar University, Cairo, Egypt.

\section{Experimental animals:}

The experiment was carried out on 18 male albino rats of Rattus rattus strain weighing 130-140 gm that were obtained from animal farm of El-Nile Company for Pharmaceutical Product (El-Nile, Cairo, Egypt). Animals were housed in metallic cages and maintained under standard condition of temperature, humidity and natural light/ dark cycle along the experimental period. Food and water were made available throughout the experiment ad libitum. The animals were left to acclimatize for one week before starting the experiment.

\section{Experimental design:}

In current study, 18 male Albino rats were divided into 3 groups (6 rats in each group) as follows:
Group 1(control group): comprised of normal rats and maintained on standard pellet diet and tap water $a d$ libitum for 30 days.

Group 2: rats received orally Fenugreek oil $(1 \mathrm{ml} / \mathrm{kg}$ body weight) for 30 days.

Group 3: rats received orally soymilk $(1 \mathrm{ml} / \mathrm{kg}$ body weight) for 30 days.

\section{Body weight measurement:}

Body weight of the animals was recorded before and at the end of the experimental duration.

\section{Blood sample collection:}

At the end of the experimental period, the blood samples were collected from the retro-orbital sinus of anesthetized rats (by ether) after overnight fasting. Serum was separated by centrifugation at $2500 \mathrm{~g}$ for 15 minutes at room temperature.

\section{Biochemical analysis}

Assessment of biochemical parameters:

In the present study, total protein (TP) and albumin concentration were estimated and then serum globulin concentrations were calculated according to the formula:

$$
\begin{array}{r}
\text { Globulin }(g / d l) \\
=\text { total protein }(g \\
/ d l)- \text { albumin }(g / d l) .
\end{array}
$$

Aspartate aminotransferase (ASAT) and alanine aminotransferase (ALAT) activities, creatinine and Blood Urea Nitrogen (BUN) concentrations as well as lipid profile; total cholesterol, triglycerides and highdensity lipoprotein cholesterol (HDL-C) were also determined. All parameters were estimated using BIO MERIEUX SA kits, France.

The ratio of serum albumin/ globulin was determined. However, ratios of total cholesterol/ highdensity lipoprotein (risk factor 1) and low-density lipoprotein/high-density lipoprotein (risk factor 2) were also calculated after calculation of serum LDL-C (lowdensity lipoprotein cholesterol) and VLDL (very low density lipoprotein) cholesterol using the Friedwald $\boldsymbol{e t}$ $\boldsymbol{a l} .^{(14)}$ and Norbert ${ }^{(15)}$ formulas, respectively as following:

Friedewald's equation:

$$
L D L(m g / d l)=T C-(H D L+[T G / 5]) .
$$

Norbert equation:

TC/HDL (risk factor 1)

$$
V L D L=T G / 5 \text {. }
$$

LDL/HDL (risk factor 2)

\section{Hormonal assay:}

Estimation of serum luteinizing hormone (LH), follicles-stimulating hormone (FSH) and testosterone (T) levels were estimated by using standard assay kits. All kits used for hormonal assay were from MONOBIND Inc. lake forest CA 92630, USA. 


\section{Sperm collection and evaluation:}

The left caudal epididymis was separated and the total recovered sperm volume during $4 \mathrm{~h}$ of incubation in normal saline (volume $=1 \mathrm{ml}, 35-37^{\circ} \mathrm{C}$ ) was calculated. The sperm concentration was determined by the conventional method using a hemocytometer chamber for the red blood cell count. The right epididymis was finely minced by anatomical scissors in $1 \mathrm{ml}$ of warmed isotonic saline in a petridish. The sperm progressive motility (SPM) was estimated by evaluating 4 fields of sperm droplet under a cover-slip on a warm glass slide $\left(35-37^{\circ} \mathrm{C}\right)$ under light microscopy $(\times 40)$.

The sperm vitality was assayed using a conventional procedure of eosin B-nigrosin stain (1.67\% eosin, $10 \%$ nigrosin, and $0.1 \mathrm{M}$ sodium citrate) under $\times 100$ magnification and 100s sperm were counted. All of the sperm evaluation procedures were carried out based on the World Health Organization manual for human sperm analysis with some modifications ${ }^{(\mathbf{1 6 )}}$.

\section{Ethical approval}

The study was approved by the Ethics Board of AlAzhar University. This study was conducted in accordance with ethical procedures and policies approved by Animal Care and Use Committee of Faculty of Medicine, Al-Azhar University, Cairo, Egypt.

\section{Statistical analysis:}

The statistical package (SPSS) program, version 19. The results were expressed as Mean \pm SEM. Data were analyzed by t-test and confidence level were accepted at $95 \%$ and $99 \%$ interval.

\section{RESULTS}

The data in table (1) showed the body weightpercentage change and fasting blood sugar level of animals administered fenugreek oil and soymilk. The animals in group 2 showed a significant $(\mathrm{p}<0.05)$ decrease in body weight compared to the control group while the animals in group 3 showed a non-significant increase compared to the control group. The fasting blood sugar results showed a highly significant $(\mathrm{p}<0.01)$ decrease in group 2 animals while group 3 animals showed a non-significant decrease compared to the control group.

Table (1): Changes \% of body weight and FBS levels in the control and treated groups

\begin{tabular}{cccc}
\hline Parameters & Control & Fenugreek oil & Soy Milk \\
\hline Body weight & $\mathbf{1 3 7 . 6} \pm \mathbf{0 . 4}$ & $\mathbf{9 2 . 3} \pm \mathbf{0 . 8}$ & $\mathbf{1 4 1 . 0 \pm \mathbf { 0 . 0 1 }}$ \\
\% of change & & $\mathbf{- 3 2 . 9 \%}$ & $\mathbf{2 . 4 \%}$ \\
\hline FBS $(\mathrm{mg} / \mathrm{dl})$ & $\mathbf{9 4 . 0} \pm \mathbf{2 . 8}$ & $\mathbf{4 2 \pm 1 . 8 * *}$ & $\mathbf{8 9 \pm 2 . 0}$ \\
\% of change & & $\mathbf{- 5 5 . 3 \%}$ & $\mathbf{- 5 . 3 \%}$ \\
\hline
\end{tabular}

The data in table (2) showed the levels of alanine aminotransferase (ALAT) and aspartate aminotransferase (ASAT) in the animals administered fenugreek oil and soymilk. Group 2 and group 3 animals showed non-significant decrease in ALAT and ASAT respectively compared to the control group.

Table (2): Changes in the ALAT and ASAT levels in the control and treated groups

\begin{tabular}{|c|c|c|c|}
\hline Parameters & Control & Fenugreek oil & Soy Milk \\
\hline $\begin{array}{l}\text { ALAT(U/L) } \\
\% \text { of change }\end{array}$ & $22.5 \pm 0.6$ & $\begin{array}{c}19.0 \pm 0.50 \\
-15.5 \%\end{array}$ & $\begin{array}{c}21.5 \pm 0.6 \\
-4.4 \%\end{array}$ \\
\hline $\begin{array}{l}\text { ASAT(U/L) } \\
\% \text { of change }\end{array}$ & $33.5 \pm 0.5$ & $\begin{array}{c}32.1 \pm 0.56 \\
-4.1 \%\end{array}$ & $\begin{array}{c}32.6 \pm 0.8 \\
-2.6 \%\end{array}$ \\
\hline
\end{tabular}

The results in table (3) showed changes in the level of blood urea nitrogen (BUN) and creatinine. The animals in group 2 and 3 showed non-significant decrease in BUN and creatinine concentrations compared to the control group.

Table (3): Changes in BUN and Creatinine levels in the control and treated groups

\begin{tabular}{cccc}
\hline Parameters & Control & Fenugreek oil & Soy Milk \\
\hline BUN $(\mathrm{mg} / \mathrm{dl})$ & $\mathbf{2 0 . 3} \pm \mathbf{0 . 2}$ & $\mathbf{1 9 . 0 \pm 0 . 4}$ & $\mathbf{1 9 . 8} \pm \mathbf{0 . 3 5}$ \\
\% of change & & $\mathbf{- 6 . 4 \%}$ & $\mathbf{- 2 . 5 \%}$ \\
\hline Creatinine $(\mathrm{mg} / \mathrm{dl})$ & $\mathbf{0 . 7} \pm \mathbf{0 . 2}$ & $\mathbf{0 . 6} \pm \mathbf{0 . 0 1}$ & $\mathbf{0 . 6} \pm \mathbf{0 . 3}$ \\
$\%$ of change & & $\mathbf{- 1 4 . 3 \%}$ & $\mathbf{- - 1 4 . 3 \%}$ \\
\hline values represent mean + SE (stander error) $\left(p^{* *}<0.01, p^{*}<0.05\right.$, as compared to control group) & &
\end{tabular}

Values represent mean $\pm \mathrm{SE}$ (stander error). ( $\mathrm{p}^{* *}<0.01, \mathrm{p}^{*}<0.05$, as compared to control group). 
The data in table (4) showed the lipid profile of the animals administered fenugreek oil and soymilk. The results showed a highly significant decrease $(\mathrm{p}<0.01)$ in TC, TG, LDL, LDL/ HDL. A highly significant increase in HDL was also recorded in group 2 while group 3 animals showed a significant decrease $(p<0.05)$ in TC, TG, LDL, LDL/ HDL and a significant increase in HDL compared to control group.

Table (4): Changes in the lipid profile levels in the control and treated groups

\begin{tabular}{|c|c|c|c|}
\hline Parameters & Control & Fenugreek oil & Soy Milk \\
\hline T G(mg/dl) & \multirow{2}{*}{$71.5 \pm 1.56$} & $45.0 \pm 2.7 * *$ & 51.0 $\pm 3.0 *$ \\
\hline$\%$ of change & & $-37.1 \%$ & $-28.6 \%$ \\
\hline HDL(mg/dl) & \multirow[t]{2}{*}{$50.3 \pm 0.33$} & $68.4 \pm 0.001 * *$ & $63.7 \pm 0.4 *$ \\
\hline$\%$ of change & & $35.9 \%$ & $26.6 \%$ \\
\hline LDL(mg/dl) & \multirow[t]{2}{*}{$71.2 \pm 1.27$} & $17.4 \pm 0.54 * *$ & $40.0 \pm 0.53 * *$ \\
\hline$\%$ of change & & $-75.5 \%$ & $-43.8 \%$ \\
\hline VLDL(mg/dl) & \multirow[t]{2}{*}{$14.30 \pm 0.31$} & $9.1 \pm 0.54 * *$ & $10.2 \pm 0.62 *$ \\
\hline$\%$ of change & & $-36.3 \%$ & $-28.6 \%$ \\
\hline LDL/HDL(mg/dl) & \multirow[t]{2}{*}{$1.22 \pm 0.007$} & $0.25 \pm 0.01 * *$ & $0.62 \pm 0.01 * *$ \\
\hline$\%$ of change & & $-79.5 \%$ & $-49.1 \%$ \\
\hline TC/HDL(mg/dl) & \multirow[t]{2}{*}{$2.47 \pm 0.008$} & $1.3 \pm 0.001 * *$ & $1.7 \pm 0.01 *$ \\
\hline$\%$ of change & & $-47.3 \%$ & $-31.1 \%$ \\
\hline \multirow{2}{*}{$\mathrm{TC}(\mathrm{mg} / \mathrm{dl})$} & \multirow{2}{*}{$141.3 \pm 0.42$} & $95.0 \pm 0.001 * *$ & $114.0 \pm 0.001 *$ \\
\hline & & $-32.7 \%$ & $-23.9 \%$ \\
\hline
\end{tabular}

The data in table (5) showed the protein profile of the animals treated with fenugreek oil and soymilk. The result showed a non-significant change in total protein, albumin, globulin and albumin $\backslash$ globulin ratio in the treated groups 2 and 3 animals compared to the control animals.

Table (5): Changes in the total protein, albumin, globulin, albumin/globulin and albumin/globulin levels in the control and treated groups

\begin{tabular}{cccc}
\hline Parameters & Control & Fenugreek oil & Soy Milk \\
\hline Total protein $(\mathrm{g} / \mathrm{dl})$ & $6.4 \pm 0.11$ & $5.9 \pm 0.13$ & $5.2 \pm 0.29$ \\
\% of change & & $-7.8 \%$ & $-18.7 \%$ \\
\hline Albumin $(\mathrm{g} / \mathrm{dl})$ & $3.7 \pm 0.11$ & $3.4 \pm 0.09$ & $3.2 \pm 0.10$ \\
\% of change & & $-8.1 \%$ & $-13.5 \%$ \\
\hline Globulin $(\mathrm{g} / \mathrm{dl})$ & $2.7 \pm 0.18$ & $2.5 \pm 0.18$ & $2.0 \pm 0.26$ \\
$\%$ of change & & $-7.4 \%$ & $-25.5 \%$ \\
\hline Albumin/Globulin $(\mathrm{g} / \mathrm{dl})$ & $1.3 \pm 0.1$ & $1.4 \pm 0.4$ & $1.6 \pm 0.1$ \\
$\%$ of change & & $7.6 \%$ & $23.1 \%$ \\
\hline
\end{tabular}

The data in table (6) showed a highly significant $(\mathrm{p}<0.01)$ decrease in FSH, LH and testosterone in group 2 animals. Group 3 animals showed a highly significant $(\mathrm{p}<0.01)$ decrease in FSH, a significant $(\mathrm{p}<0.05)$ decrease in testosterone and non-significant change in LH when compared to control the animals.

Table (6): Changes in the FSH, LH and Testosterone levels in the control and treated groups

\begin{tabular}{cccc}
\hline Groups Parameters & Control & Fenugreek oil & Soy Milk \\
\hline FSH $(\mathrm{ng} / \mathrm{ml})$ & $2.9 \pm 0.1$ & $2.0 \pm 0.1^{* *}$ & $2.1 \pm 0.1^{* *}$ \\
$\%$ of change & & $-31.0 \%$ & $-27.6 \%$ \\
\hline $\mathrm{LH}(\mathrm{ng} / \mathrm{ml})$ & $1.9 \pm 0.1$ & $1.5 \pm 0.1^{*}$ & $1.7 \pm 0.1$ \\
$\%$ of change & & $-21.1 \%$ & $-10.5 \%$ \\
\hline Testosterone $(\mu \mathrm{u} / \mathrm{dl})$ & $3.9 \pm 0.2$ & $3.0 \pm 0.2^{* *}$ & $3.1 \pm 0.1^{*}$ \\
$\%$ of change & & $-23.1 \%$ & $-20.5 \%$ \\
\hline
\end{tabular}

The data in table (7) showed a significant $(\mathrm{p}<0.05)$ decrease in sperm count in group 2 and 3 animals when compared to the control rats. 
ejhm.journals.ekb.eg

Table (7): Sperm count in the control and treated groups.

\begin{tabular}{cccc}
\hline Parameters & Control & Fenugreek oil & Soy Milk \\
\hline $\begin{array}{c}\text { Sperm count* } 10^{6} / \mathrm{ml} \\
\% \text { of change }\end{array}$ & 100 & 50 & 65 \\
& & $-50 \%$ & $-35 \%$
\end{tabular}

\section{DISCUSSION}

In this study, fenugreek supplementation reduced the body weight of the animals. The probable mechanism of fenugreek decreasing total body weight may be that fenugreek flushes out the carbohydrates from the body before they enter the blood stream resulting in weight loss and because it contains a high proportion (40\%) of soluble fiber. This fiber forms a gelatinous structure (similar to gaur gum), which may have effects on slowing the digestion and absorption of food from the intestine and create a sense of fullness in the abdomen, thus suppresses appetite and promotes weight loss ${ }^{(17)}$.

In the present study, fenugreek reduced blood sugar in vitro the amino acid 4- hydroxyisoleucine in fenugreek may have increased glucose-induced insulin release in human and rat pancreatic islet cells. It has been observed that 4-hydroxyisoleucine extracted from fenugreek seeds possess insulin tropic activity ${ }^{(\mathbf{1 8})}$. This amino acid appeared to act only on pancreatic beta cells. In humans, fenugreek seeds exert hypoglycemic effects by stimulating glucose-dependent insulin secretion from pancreatic beta cells as well as by inhibiting the activities of alpha-amylase, an intestinal enzymes involved in carbohydrate metabolism ${ }^{(\mathbf{1 9})}$. Another study showed that the hypoglycemic effect of fenugreek is thought to be largely due to its high content of soluble fiber, which acts to decrease the rate of gastric emptying thereby delaying the absorption of glucose from the small intestine ${ }^{(20)}$.

The findings in this study showed a decrease in total cholesterol, total glycerol, LDL and VLDL in both experimental groups treated with fenugreek oil and soymilk while the HDL was significantly increased in both groups compared to the control group. These findings are in line with reports from Eidia $\boldsymbol{e t} \boldsymbol{a l}{ }^{(\mathbf{( 2 1 )})}$ and Xue et $\boldsymbol{a l} .{ }^{(22)}$ who demonstrated that extracts of fenugreek decreased triglycerides, total cholesterol, LDL and increased HD-c in diabetic rats. Elman ${ }^{(23)}$ also reported that fenugreek powder also reduced total cholesterol and LDL-c concentrations and increased HDL in a dose-dependent manner in rats. The hypocholesteremic effect of fenugreek oil as observed in this study may be attributed to the saponin content of fenugreek ${ }^{(24)}$, which has been reported to possess hypocholesteremic activity ${ }^{(\mathbf{2 5})}$ as a result of its ability to form insoluble lipid complexes thereby preventing absorption of lipid. The hypocholesteremic property of fenugreek may also be as a result of the crude fiber content that has been reported to lower cholesterol levels ${ }^{(23)}$ by blocking cholesterol absorption in the intestine $^{(26)}$.

Soymilk has also been reported to possess lipid lowering effect ${ }^{(27)}$, which may be attributed to soy isoflavones, soy protein and dietary fiber of soy that upregulates lipid receptors thereby reducing serum lipid levels. The findings in this study also showed reduction in LDL/HDL and TC/HDL ratio in both experimental groups compared to the control group.

Changes in hormonal levels in this study showed a significant reduction in follicle-stimulating hormone (FSH) and testosterone in both experimental groups compared to the control group while the luteinizing hormone (LH) levels was only significantly reduced in the group treated with fenugreek oil compared to the control group.

Kassem et al. ${ }^{(28)}$ revealed that Trigonella foenumgraecum has decreased plasma androgen concentration. This agrees with our present study that fenugreek decreased the sperm count and this may be due to the presence of steroidal oestrogen like saponins. This may explain the effect of Trigonella foenum-graecum seeds ethanolic extract on serum testosterone and sperm count, or may be due to the fact that Trigonella foenum-graecum increases the prolactin levels. Higher levels of prolactin tends to inhibit production of gonadotropin-releasing hormone $(\mathrm{GnRH})$ leading to decrease in both FSH and LH and thereby decrease spermatogenesis and decrease testosterone level. This agrees with a study by Kassem $\boldsymbol{e t}$ al. ${ }^{(28)}$, which reported that administering Trigonella foenum-graecum seeds to animals significantly decreased sperm count.

Another study by Yi et al. ${ }^{(29)}$ reported a decrease in testosterone level in animals treated with soy flour. Pollard et al. ${ }^{(30)}$ also observed significant reduction in serum testosterone in Wistar rats fed soy protein isolates. Isoflavones, including genistein and daidzein, have previously been shown to inhibita-reductase and $17 \mathrm{~b}$-hydroxy steroid dehydrogenase activities in human tissue $^{(27)}$. Theprecursors of these compounds are present in relatively large amounts in soy and its products such as tofu andsoymilk. These are metabolized into aglycones by gut bacterial enzymes and then absorbed to exert physiological activity in the human body.

Genistein and daidzein, which are found in large amount in soy milk have phytoestrogen activity and antiandrogenic effect, which has been shown to inhibitareductase and 17- hydroxy steroid dehydrogenase activities in human tissue ${ }^{(31)}$, and also reduce the number of Leydig cells, which areresponsible for the production of testosterone. The findings in this study suggest that the decrease in the FSH and testosterone level lead to decrease in sperm count. 


\section{CONCLUSION}

The findings of this study suggest that fenugreek oil and soy milk have high potential of negatively altering the lipid profile and increasing the health risks associated with a poor lipid profile. In addition, both the fenugreek oil and soymilk possess potentials that can impair hormonal functions and fertility as demonstrated in this study.

\section{REFERENCES}

1. Food Standards Agency (2002): McCance and Widdowson's 'The Composition of Foods'. 6th ed. Royal Society of Chemistry; Cambridge. Available at: https://www.researchgate.net/publication/237123505_McCa nce_and_Widdowson's_The_Composition_of_Foods_Sixth_Edition

2. Rajni K, Arif B (2015): The Benefits of Consuming Soya Milk- A Review. Trends in Biosciences, 8(5): 1159-1162.

3. Cassidy A, Faughnan M (2000): Phytoestrogen through the life cycle. Proceeding of the Nutrition Society, 59:489-496.

4. Malhotra SK (2011): Fenugreek (Trigonella foenumgraecum L.). In book: Genetic Resources, Chromosome Engineering and Crop Improvement. $1^{\text {st }}$ Edition. Chapter 4, CRC Press, Pp: 801-846.

5. Sharma RD, Raghuram TC, Rao NS (1990): Effects of fenugreek seeds on blood glucose and serum lipid in type I diabetes. Eur J clin nutr., 44: 301-306

6. Ajabnoor MA, Tilmisany AK (1998): Effect of Trigonella foenum-graecum on blood glucose levels in normal and alloxan-diabetic mice. J Ethnopharmacol., 22: 45-49.

7. Belguith-Hadriche O, Bouaziz M, Jamoussi K, El Feki A, Sayadi S, Makni-Ayedi F (2010): Lipid-lowering and antioxidant effects of an ethyl acetate extract of fenugreek seeds in high cholesterol- fed rats. J Agric Food Che., 58(4):2116-2122.

8. Pandian RS, Anuradha CV, Viswanathan P (2002): Gastroprotective effect of fenugreek seeds (Trigonella foenum graecum) on experimental gastric ulcer in rats. $\mathbf{J}$ Ethnopharmacol., 81: 393-397.

9. Max B (1992): This and That: The essential pharmacology of herbs and spices. Trends. Pharma Sci., 13: 15-20.

10. Suresh $P$, Kavitha ChN, Babu SM, Reddy VP, Latha AK (2012): Effect of ethanol extract of Trigonella foenum graecum (Fenugreek) seeds on Freund's adjuvant-induced arthritis in albino rats. Inflammation, 35(4):1314-1321.

11. Handa T, Yamaguchi K, Sono Y, Yazawa K (2005): Effects of fenugreek seed extract in obese mice fed a high-fat diet. Biosci. Biotechbol. Biochem., 69(6):1186-1188.

12. Geetha M, Suneel KR, Krupanidhi AM, Muralikrishna K S, Avin A P, Prashanth P (2011): Effect of Fenugreek on Total Body and Organ Weights: A Study on Mice. Pharmaco., 3:747-752.

13. Granick B, Neubauer D, Der Marderosian A (Eds) (1996): The Lawrence review of natural products. St. Louis: Facts and Comparisons. Pp: 1-3.

14. Friedwalds WT, Levy RI, Fredrickson DS (1999): Estimation of the concentration of low-density lipoprotein cholesterol in plasma, without use of the preparative ultracentrifuge. Clin. Chem., 18:499-502.

15. Norbert WT (1995): Clinical guide to laboratory tests. $3^{\text {rd }}$ ed. Saunders W.B. company, Philadelphia, 35:972-972.

16. WHO (2010): WHO laboratory manual for the examination and processing of human semen. 5th ed. Geneva, Swittzerland: WHO press, Pp: 22-44.

17. Geetha M, Suneel KR, Krupanidhi AM, Muralikrishna KS, Avin AP, Prashanth P (2011): Effect of Fenugreek on Total Body and Organ Weights: A Study on Mice. Pharmacology online, 3: 747-752.

18. Sauvaire Y, Petit $P$, Broca $C$ (1978): 4-hydroxy-isoleucine: A novel amino acid potentiator of insulin secretion. Diabetes, 47: 206-210.

19. Ajabnoor MA, Tilmisany AK (1988): Effect of Trigonella foenum graceum on blood glucose levels in normal and alloxan-diabetic mice. J Ethnopharmacol., 22:45-49.

20. Tim KR (1998): Herbal support for diabetes management. Adva Nutr Public, 6: 8-12.

21. Eidia A, Eidib M, Sokhteha M (2007): Effect of fenugreek (Trigonella foenum-graecum L) seeds on serum parameters in normal and streptozotocin-induced diabetic rats. Nutrition Research, 27:728-733.

22. Xue W, LiX, Zhang J, Liu Y, Wang Z, Zhang R (2007): Effect of Trigonella foenum-graecum (fenugreek) extract on blood glucose, blood lipid and hemorheological properties in streptozotocin-induced diabetic rats. Asia Pac.J.Clin. Nutr,. 16:422-423.

23. Elmnan A, Balgees A, Mangara JL (2012): Effect of Fenugreek (Trigonella foenm greacum) Seed Dietary Levels on Lipid Profile and Body Weight Gain of Rats. Pakistan Journal of Nutrition, 11:1004-1008.

24. Sharma RD (1986): An evaluation of hypocholesterolemic factor of fenugreek seeds (T. foenum graecum) in rats. Nutr. Rep. Int., 33: 669-677.

25. Al-Habori M, Al-Aghban AM, Al-Mamary M (1998): Effect of fenugreek seeds and its extracts on plasma lipid profile: a study on rabbits. Phytother. Res., 12:572-575.

26. Lanksy PS, Schulcher H, Phillipson JD, Loe WD (1992): Plant that lowers cholesterol. Acta-Horticulturae, 332:131136.

27. Bakhtiary A, Yassin Z, Hanachi P, Rahmat A, Ahmad Z, Jalali F (2012): Effects of soy on metabolic biomarkers of cardiovascular disease in elderly women with metabolic syndrome. Arch Iran Med., 15:462-468.

28. Kassem A, Al-Aghbari A, AL-Habori MT, Al-Mamary M (2006): Evaluation of the potential antifertility effect of fenugreek seeds in male and female rabbits. Contraception, 73: 301- 306.

29. Yi MA, Son HM, Lee JS, Kwon CS, Lim JK, Yeo YK, Park YS, Kim JS (2002): Regulation of male sex hormone levels by soy isoflavones in rats. Nutr Cancer, 42:206-210.

30. Pollard M, Wolter W, Sun L (2000): Prevention of induced prostaterelated cancer by soy protein isolate/isoflavonesupplemented diet in Lobund-Wistar rats. In Vivo, 14:389392.

31. Fatima IZ, Addou S, Bouferkas Y, Kheroua O, Saidi D (2014): Effect of the consunption of milk of soya on the male fertility of Swiss mice. Int J Pharm Pharm Sci., 6: 669-676. 